\title{
Renal replacement therapy for acute kidney injury
}

Shigeo Negi i* Daisuke Koreeda ${ }^{2}$, Sou Kobayashi ${ }^{1}$, Yu Iwashita ${ }^{1}$ and Takashi Shigematu ${ }^{1}$

\begin{abstract}
The annual incidence of acute kidney injury (AKI) has been increasing as the population ages. Despite advances in critical care and dialysis technology, the mortality remains unacceptably high in patients with AKI during the past few decades. Renal replacement therapy (RRT) is performed to treat patients with severe AKI and multiple organ failures, as well as to remove fluid in patients with fluid overload including those with acute heart failure and lung edema in the intensive care unit (ICU). The mortality in patients with AKI requiring RRT is higher than $50 \%$. RRT strategies in patients with AKI depend on various conditions. However, there is little consensus on when to start and stop RRT, its optimal dose, and the choice of different RRT modalities (intermittent versus (vs.) continuous) in patients with AKI. Patients with AKI in the ICU are preferentially treated with continuous rather than intermittent RRT (IRRT), usually because of hemodynamic stability and steady of solute clearance. At present, the type and dose of RRT are dependent on the experience of the attending clinicians, including intensivists and nephrologists.
\end{abstract}

Keywords: Acute kidney injury, Renal replacement therapy, Continuous renal replacement therapy, Intermittent renal replacement therapy, Dose of renal replacement therapy, Modality of renal replacement therapy

\section{Background}

Acute kidney injury (AKI) is defined as a rapid decline in glomerular filtration rate occurring over a period of minutes to days, with retention of blood urea nitrogen and serum creatinine ( $\mathrm{SCr}$ ). AKI is one of the most common and serious complications of critically ill patients in intensive care unit (ICU). Approximately $4 \%$ of ICU patients develop AKI requiring renal replacement therapy (RRT) [1]. As no specific pharmacologic therapy is effective in AKI patients, their care is limited to supportive management in which RRT plays a central role. Despite advances in the understanding and management of AKI including introduction of RRT, mortality in ICU patients with AKI remains largely unimproved and unacceptably high. Moreover, mortality in ICU patients with AKI severe enough to require RRT has been reported to be as high as $80 \%[2,3]$. However, several issues regarding RRT remain to be solved in patients with AKI (Table 1). In particular, no consensus has been reached on the timing of the initiation and the discontinuation of RRT, or

\footnotetext{
* Correspondence: shigeon@wakayama-med.ac.jp

${ }^{1}$ Division of Nephrology, Department of Internal Medicine, Wakayama Medical University, 811-1 Kimiidera, Wakayama-City, Wakayama-Prefecture 641-8509, Japan

Full list of author information is available at the end of the article
}

its optimal dose, modality (intermittent or continuous), mode (hemodiafiltration (HDF), hemofiltration (HF), hemodialysis (HD)), and type of dialysis membranes for AKI. This review will discuss RRT for AKI in critically ill patients.

\section{Review \\ Timing of initiation and discontinuation of RRT in critically ill patients with AKI}

Critically ill patients with AKI often require RRT, but there is no consensus to guide clinicians on the timing of initiation of RRT. The traditional indications for RRT in critically ill patients with AKI include (1) volume overload resistant to diuretic agents, (2) sudden hyperkalemia, (3) severe metabolic acidosis, and (4) uremic manifestations, including encephalopathy, pericarditis, and convulsion. Several studies have examined the timing of RRT initiation in AKI patients in the ICU. It is unclear whether the early initiation of RRT improves survival and renal recovery rates [4-9]. These studies, however, differ in their definition of early and late initiation. In most studies, the timing of RRT was assessed using conventional serum biomarkers (e.g., serum urea and SCr levels), urine volume, and the time from ICU admission to the start of RRT. 
Table 1 The controversial issues regarding RRT in AKI

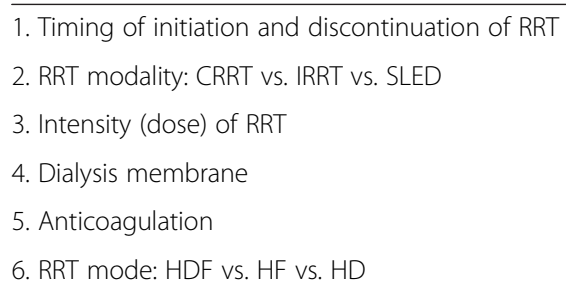

$R R T$ renal replacement therapy, AKI acute kidney injury, CRRT continuous renal replacement therapy, IRRT intermittent renal replacement therapy, SLED sustained low efficiency dialysis, HDF hemodiafiltration, HF hemofiltration, $H D$ hemodialysis

Until recently, three randomized controlled trials (RCTs) evaluated whether the early initiation of RRT improved mortality in patients with AKI $[4,5,9]$. In one study, Bourman et al. randomized 106 critically ill patients with AKI into three groups, 35 were treated with early high-volume HF (HVHF), 35 with early low-volume HF, and 36 with late low-volume HF [4]. Early initiation of RRT was defined as within $12 \mathrm{~h}$ of oliguria (urine output $<30 \mathrm{~mL} / \mathrm{h}$ for $6 \mathrm{~h}$, or creatinine clearance $<20 \mathrm{~mL} / \mathrm{min}$ ), whereas late initiation was defined as patient fulfillment of the conventional criteria for RRT. Compared with late initiation, early initiation of RRT did not improve mortality and dialysis dependence. A second study, in Japan, evaluated whether early initiation of RRT affected survival in 28 patients who developed AKI after cardiac surgery [5]. Patients were randomized to an early-start group, receiving RRT when urine volume was $<30 \mathrm{~mL} / \mathrm{h}$ for $3 \mathrm{~h}$, or conventional-start group who waited to receive RRT until urine volume was $<20 \mathrm{~mL} / \mathrm{h}$ for $2 \mathrm{~h}$. Early RRT significantly improved patient survival $(p<0.01)$, indicating that the timing of RRT initiation in post-cardiac surgery patients with AKI should be determined by urine volume not by $\mathrm{SCr}$ levels. In the HEROICS trial, 224 patients with severe shock requiring high-dose catecholamines following cardiac surgery were randomized to early HVHF $(80 \mathrm{~mL} / \mathrm{kg} / \mathrm{h})$ for $48 \mathrm{~h}$ followed by standard-volume continuous veno-venous hemodiafiltration (CVVHDF) $(n=112)$ or to standard care with delayed CVVHDF $(n=112)$ [9]. Patients in the latter group received CVVHDF when $\mathrm{SCr}$ was $>354 \mu \mathrm{mol} / \mathrm{L}$ $(>4 \mathrm{mg} / \mathrm{dL}$ ) or had increased threefold from preoperative levels; when urine output was $<0.3 \mathrm{~mL} / \mathrm{kg} / \mathrm{h}$ for $24 \mathrm{~h}$; when urea was $>36 \mathrm{mmol} / \mathrm{L}$; or when they experienced life-threatening hyperkalemia. The 30-day mortality was $36 \%(40 / 112)$ in both groups $(p=1.00)$, and there were also no significant differences in 60- and 90-day mortality.

Several observational studies have assessed the relationships between the timing of RRT and mortality and renal recovery in critically ill patients with AKI requiring RRT [6-8]. The largest prospective cohort study, involving patients at 54 ICUs in 23 countries, showed that the timing of RRT influenced outcomes in critically ill patients with severe AKI [7]. In this study, the timing of RRT initiation was stratified as early or late based on the median SCr and serum urea levels. No differences in mortality were observed between the early and late groups stratified by serum urea levels. When the timing of RRT was stratified by $\mathrm{SCr}$ levels, however, late RRT was associated with lower mortality than the early RRT. When the timing of RRT was defined by the median time from ICU admission to start of RRT, the crude mortality was higher for late than early RRT (72.8 versus (vs.) $58.9 \%$, $p<0.001$ ).

A systematic review and meta-analysis showed that early initiation of RRT in critically ill patients with AKI may have a beneficial impact on survival compared with late initiation [10]. However, this conclusion was based on only two RCTs, with significant heterogeneity $[4,5]$. These findings stress the need for further well-designed RCTs assessing the effects of RRT timing on patient survival.

On the other hand, no consensus has been reached on the timing of discontinuation of RRT for AKI. As no RCTs to date have evaluated the timing of discontinuation, the factors determining the decision to stop RRT and the effects of the timing of discontinuation on patient outcomes and recovery of renal function remain unclear. Only three observational studies have investigated the discontinuation of RRT in critically ill patients with AKI. Uchino et al. examined 529 patients who survived initial therapy among 1006 patients treated with continuous renal replacement therapy (CRRT) [11]. They classified 313 AKI patients weaned successfully from CRRT for at least 7 days as the success group and 216 AKI patients needed repeat CRRT within 7 days of discontinuation as the repeat-RRT group. Patients in the success group had lower ICU and hospital mortality compared with repeat-RRT group $(p<0.0001)$, and those in the success group had lower SCr, urea, and higher urine output at the discontinuation of CRRT. Multivariate logistic regression analysis showed that urine output (odds ratio (OR), 1.078 per $100 \mathrm{~mL} /$ day) was the most significant predictor of successful discontinuation of CRRT. Wu et al. showed risk factors for early redialysis in 94 patients with AKI who were weaned from RRT after major surgery [12]. The independent predictors for resuming dialysis within 30 days were (1) longer duration of dialysis, (2) higher Sequential Organ Failure Assessment (SOFA) score, (3) oliguria (urine output $<100 \mathrm{~mL} / 8 \mathrm{~h}$, and (4) age over 65 years. Kawarazaki et al. examined the predictive factors of early kidney recovery (within $48 \mathrm{~h}$ ) after CRRT initiation in AKI patients in a multicenter retrospective observational study of 14 Japanese ICUs. In multivariable regression analysis, urine output $(\mathrm{mL} / \mathrm{h})$, duration between ICU admission and CRRT initiation (days), and the SOFA score were related to early kidney recovery (OR 1.02, 0.65, 0.87; $95 \%$ confidence interval 
(CI) 1.01-1.03, 0.43-0.87, 0.78-0.96; $p<0.001,0.02$, 0.007 ; respectively) [13].

\section{Optimal dose of RRT for AKI}

Until now, the optimal dose of RRT for critically ill patients with AKI remains unclear. Whether high dose of RRT for AKI leads to the improvement of survival and renal recovery remains controversial. In the first study conducted by Ronco et al. evaluating the intensity of CRRT, 425 critically ill patients with AKI at a single center in Italy who were treated with continuous veno-venous hemofiltration (CVVHF) were randomized to three groups differing in filtration rate $(20,35$, or $45 \mathrm{~mL} / \mathrm{kg} / \mathrm{h})$ [14]. The survival at 15 days after discontinuation of CRRT was significantly lower in the lowest dose (41\%) than in the intermediate $(57 \%, p=0.007)$ and highest (58\%, $p=0.0013$ ) dose groups but did not differ in the latter two groups. These findings suggest that a filtration rate $\geq 35 \mathrm{~mL} / \mathrm{kg} / \mathrm{h}$ was recommended for critically ill patients with AKI requiring CRRT. Since then, rate at $35 \mathrm{~mL} / \mathrm{kg} / \mathrm{h}$ has come to be known as Roco dose widely all over the world. Three subsequent RCTs evaluated the optimal dose of CRRT for AKI $[4,15,16]$. However, all three had small numbers of patients, making them insufficiently powerful to show the effect of high-dose CRRT on survival. One single-center study compared CVVHF (mean prescribed filtration of $25 \pm 5 \mathrm{~mL} / \mathrm{kg} / \mathrm{h}$ ) with CVVHDF (mean prescribed filtration of $24 \pm$ $6 \mathrm{~mL} / \mathrm{kg} / \mathrm{h}+$ mean prescribed dialysis dose of $18 \pm$ $5 \mathrm{~mL} / \mathrm{kg} / \mathrm{h}$ ) in 206 patients with AKI [15]. This study showed that the patient survival was significantly higher in patients who received CVVHDF than CVVHF, both at 28 days (59 vs. $39 \%, p=0.03$ ) and 90 days (59 vs. $34 \%$ $p=0.0005)$. In contrast, the other two studies failed to show that increased CRRT dose improved survival in patients with AKI $[4,16]$.

Moreover, in 2008 and 2009, two major multicenter RCTs evaluating the impact of RRT dose on patient survival were conducted in the USA and in Australia and New Zealand [17, 18]. These two trials were the first to provide high-quality evidence guiding the prescribed dose of CRRT in patients with severe AKI. The Veterans Affairs/National Institutes of Health Acute Renal Failure Trial Network (ATN) study randomly assigned critically ill patients with AKI requiring RRT to intensive therapy $(n=563)$ or less intensive therapy $(n=561)$ [17]. In the intensive therapy group, pre-dilution CVVHDF was prescribed to provide a total effluent flow rate of $35 \mathrm{~mL} / \mathrm{kg} / \mathrm{h}$, along with intermittent HD (IHD) and sustained lowefficiency dialysis (SLED) six times per week. In the less intensive therapy group, pre-dilution CVVHDF was prescribed to provide a total effluent flow rate of $20 \mathrm{~mL} / \mathrm{kg} / \mathrm{h}$, as well as IHD and SLED three times per week. The primary endpoint was death from any cause by 60 days, and the secondary endpoint included in-hospital death and renal recovery. Of the patients in the intensive and less intensive therapy groups, $302(53.6 \%)$ and 289 (51.5\%), respectively, died within 60 days (OR 1.09, 95 \% CI 0.86$1.40, p=0.47)$. Moreover, there were no significant differences in renal recovery and hospital mortality among both groups. This trial had several limitations, including different dialysis modes (HD, SLED, CVVHDF) and the non-report of the members of patients in each group receiving each type of RRT.

The Randomized Evaluation of Normal versus Augmented Level (RENAL) Replacement Therapy Study is the largest RCT to date evaluating the dose of CRRT for AKI [18]. The 1508 participants with AKI requiring RRT were randomly assigned to post-dilution CVVHDF with an effluent flow of $40 \mathrm{~mL} / \mathrm{kg} / \mathrm{h}$ (higher intensity therapy: $n=747$ ) or $25 \mathrm{~mL} / \mathrm{kg} / \mathrm{h}$ (lower intensity therapy: $n=$ 761). This trial also showed that higher intensity therapy did not lead to improvement in 28- and 90-day mortality compared with lower intensity therapy. The 90 -day mortality in these two groups was $44.7 \%(322 / 721)$ and $44.7 \%$ (332/743), respectively (OR 1.00, 95 \% CI $0.81-$ 1.23, $p=0.99$ ). These two large multicenter RCTs failed to show that more intensive RRT improved mortality in patients with AKI receiving RRT. Prowle et al., in a current clinical review, suggested that CRRT delivered dose of $<20 \mathrm{~mL} / \mathrm{kg} / \mathrm{h}$ should be avoided, and they recommended 20 to $25 \mathrm{~mL} / \mathrm{kg} / \mathrm{h}$ in patients with AKI requiring CRRT [19]. Similarly, in Kidney Disease: Improving Global Outcomes (KDIGO) clinical practice guidelines for acute kidney injury, delivered dose of 20 to $25 \mathrm{~mL} / \mathrm{kg} / \mathrm{h}$ should be recommended for optimal dose of CRRT in patients with AKI [20].

In Japan, however, the standard CRRT dose for patients with AKI is $600-800 \mathrm{~mL} / \mathrm{h}$, equivalent to approximately $10-13 \mathrm{~mL} / \mathrm{kg} / \mathrm{h}$ based on an average weight of Japanese patients in the ICU of $60 \mathrm{~kg}$, with health insurance paying for only a very low dose for CRRT. To date, no RCT has shown that very low doses for CRRT improved survival and renal recovery compared with standard doses in patients with AKI. However, two recent retrospective observational studies assessed whether very low-intensity CRRT was associated with improved mortality and renal recovery in patients with AKI $[21,22]$. Fujii et al. found no significant differences in ICU ( 34 vs $43 \%, p=0.37$ ) and in-hospital (36 vs $53 \%, p=0.055$ ) mortality between patients treated with very low-intensity CVVHDF (mean dose of $14.2 \mathrm{~mL} / \mathrm{kg} / \mathrm{h}$ ) and conventional CVVHDF (mean dose of $20.0 \mathrm{~mL} / \mathrm{kg} / \mathrm{h} \mathrm{[21]}$. In addition, Uchino et al. demonstrated that CRRT with mean intensity of $14.3 \mathrm{~mL} / \mathrm{kg} / \mathrm{h}$ did not exacerbate ICU and hospital mortality in patients with severe AKI requiring CRRT compared with CRRT with mean intensity of $20.4 \mathrm{~mL} / \mathrm{kg} / \mathrm{h}$ [22]. Further welldesigned prospective RCTs are needed to confirm that 
very low dose of CRRT does not reduce survival in patients with AKI.

Several recent clinical trials have assessed whether HVHF improves mortality and recovery of renal function in patients with septic AKI [23-25]. A systematic review found that HVHF, defined as a dose of $>50 \mathrm{~mL} / \mathrm{kg} / \mathrm{h}$, did not clearly improve mortality in patients with septic AKI $[26,27]$. For example, the high volume in intensive care (IVOIRE) trial, conducted at 18 ICUs in France and Belgium and the Netherlands, randomized 140 patients with septic shock requiring RRT to HVHF $(70 \mathrm{~mL} / \mathrm{kg} / \mathrm{h})$ or standard-volume hemofiltration (SVHF, $35 \mathrm{~mL} / \mathrm{kg} / \mathrm{h}$ ) [25]. HVHF, however, failed to reduce the 28-day mortality compared with conventional SVHF.

In contrast, few prospective studies have assessed the dose of IHD. Schiffl et al., in a single-center study, assigned 160 patients with AKI in an alternating fashion to receive IHD on daily or on alternate days [28]. Fourteen-day mortality after the last session of IHD was significantly lower in daily IHD group ( $28 \%)$ as compared with alternate day IHD group $(46 \%, p=0.01)$. Extended dialysis (ED) and SLED are hybrid modalities involving low dialysate and blood flow rates and prolonged duration in critically ill patients with AKI. The Hannover Dialysis Outcomes Study evaluated the relationships between dose of ED and mortality and renal recovery in patients with AKI requiring RRT [29]. One hundred fifty-six patients were randomly assigned to receive standard ED (to maintain urea levels between 120 and $150 \mathrm{mg} / \mathrm{dL}$ ) or intensified ED (to maintain urea levels $<90 \mathrm{mg} / \mathrm{dL}$ ); there were no significant differences in 14-day (70.7 vs. $70.4 \%, p=0.97)$ and 28 -day (61.3 vs. $55.6 \%, p=0.47$ ) survival between standard ED and intensified ED or in 28 -day renal recovery among survivors (63.0 vs. $60.0 \%$, $p=0.77$ ).

Other than the optimal dose of RRT for patients with AKI, clinicians who prescribe CRRT in the ICU should recognize that prescribed and delivered doses may differ. Several studies have shown that the actual delivered dose of CRRT is approximately $70-90 \%$ of the prescribed dose [30, 31]. Claure-Del Granado et al. compared delivered with prescribed doses in critically ill patients with AKI treated with CVVHDF based on urea nitrogen concentrations in dialysis fluid [30]. This trial found that the prescribed dose overestimated the actual delivered dose by $23.8 \%$, suggesting that the delivered dose should be increased 20 to $25 \%$ to achieve a prescribed dose in patients with AKI during CRRT. Treatment downtime and reductions in filter efficacy contribute to the reductions in delivered compared with prescribed dose of CRRT. The most common causes of downtime are routine CRRT circuit change, problems related to vascular access, and procedures performed outside the ICU including surgery and other diagnostic methods.

\section{RRT modality and RRT mode in patients with $A K I$}

CRRT and IHD are the mainstays of treatment strategy in patients with AKI requiring RRT in the ICU. RCTs comparing these two modalities have failed to provide evidence for the survival benefits of CRRT over IHD [32-46]. The clinical question "which is the best treatment strategy for critically ill patients with AKI requiring RRT ? CRRT or intermittent renal replacement therapy (IRRT) ?" admits of further discussion. Moreover, the relative survival advantages of $\mathrm{HDF}, \mathrm{HF}, \mathrm{HD}$, and peritoneal dialysis in critically ill patients with AKI remain unclear, with few previous RCTs comparing the effects of continuous hemodiafiltration (CHDF), continuous hemofiltration (CHF), and continuous hemodialysis (CHD) on patient mortality [47]. Newly developed hybrid technology, called extended daily dialysis (EDD)/HDF including sustained low efficiency dialysis (SLED)/HDF, has been performed in patients with AKI $[48,49]$. EDD is generally defined as extended (approximately $6-10 \mathrm{~h}$ ) HD or HDF using a conventional HD machine, blood flow rates of $100-200 \mathrm{~mL} / \mathrm{min}$, and dialysate flow rates of 200 $300 \mathrm{~mL} / \mathrm{min}$ (Table 2).

A large meta-analysis, performed by the Cochrane Collaboration, evaluated 15 RCTs involving 1550 patients with AKI [50]. This analysis showed no significant differences between patients treated with CRRT and IRRT in ICU (relative risk (RR) 1.06, $95 \%$ CI 0.90-1.26) and hospital (RR 1.01, 95 \% CI 0.92-1.12) mortality and in renal recovery. The KDIGO clinical practice guidelines for acute kidney injury in 2012 suggested that CRRT is preferable in hemodynamically unstable patients with AKI and in patients with acute brain injury or other causes of increased intracranial pressure or generalized brain edema [20].

Table 2 Standard RRT modality in Japan

\begin{tabular}{llll}
\hline & CHDF(CRRT) & IHD (IRRT) & SLED \\
\hline Blood flow $(\mathrm{mL} / \mathrm{min})$ & $80 \sim 100$ & $200 \sim 250$ & $100 \sim 200$ \\
Dialysate flow & $500 \sim 600 \mathrm{~mL} / \mathrm{h}$ & $500 \mathrm{~mL} / \mathrm{min}$ & $200 \sim 300 \mathrm{~mL} / \mathrm{min}$ \\
Replacement flow $(\mathrm{mL} / \mathrm{h})$ & $200 \sim 300$ & & \\
Treatment period $(\mathrm{h})$ & 24 & $3 \sim 5$ & $6 \sim 10$ \\
\hline
\end{tabular}

RRT renal replacement therapy, CHDF continuous hemodiafiltration, CRRT continuous renal replacement therapy, IHD intermittent hemodialysis, IRRT intermittent renal replacement therapy, SLED sustained low efficiency dialysis 
Furthermore, Surviving Sepsis Campaign Guidelines (SSCG) also suggested that CRRT and IRRT showed no differences in short-term mortality in patients with severe sepsis and AKI [51]. A current systematic review and meta-analysis evaluating 7 RCTs and 16 observational studies compared the rate of dialysis dependence among survivors [52]. Evaluation of the RCTs showed no significant differences in the rate of dialysis dependence between IRRT and CRRT (RR 1.15, 95 \% CI 0.78-1.68). In contrast, observational studies revealed that the relative risk of IRRT compared with CRRT for dialysis dependence was 1.99 (95\% CI 1.53-2.59). The largest RCT, which enrolled 360 patients with AKI, showed no difference in 60-day mortality between the CRRT and IRRT groups [40]. The most recent RCT, in which 252 patients with AKI were randomized to receive IHD $(n=$ $129)$ or $\mathrm{CVVH}(n=123)$, found that the univariate ORs for the IHD group were 1.27 (95\% CI 0.76-2.12, $p=0.36$ ) for 14-day mortality, 1.37 (95\% CI $0.82-2.27, p=0.22$ ) for 28day mortality, and 1.26 (95\% CI 0.76-2.10, $p=0.37$ ) for intrahospital mortality [46]. In this way, the newest RCT failed to show that CRRT was superior to IRRT in critically ill patients with AKI requiring RRT. In addition, a recent meta-analysis evaluated seven RCTs and ten observational studies that compared EDD with CRRT in patients with AKI [53]. Although evaluation of the RCTs revealed no significant difference in mortality between EDD and CRRT (RR 0.90, $95 \%$ CI 0.74-1.11, $p=0.3$ ), the observational studies showed that the mortality was lower in patients treated with EDD than CRRT. Further, high-quality RCTs are required to confirm these results.

Many trials have investigated the impact of the RRT modality in patients with AKI on mortality and renal recovery. In contrast, the standard criteria for RRT mode (HD, HF, HDF) in AKI patients have not yet been established. Moreover, few RCTs have revealed that any RRT mode results in higher survival than the other modes in patients with AKI. Wald et al. assigned 78 critically ill patients with AKI to CVVH group or continuous venovenous hemodialysis (CVVHD) group in Optimal Mode of clearance in critically ill patients with Acute Kidney Injury (OMAKI) study conducted in Canada [47]. Sixtyday mortality and dialysis dependence in survivors were similar between CVVH group and CVVHD group (54 vs. $55 \%$ for mortality, 24 vs.19 \% for dialysis dependence, respectively). The Beginning and Ending Supportive Therapy (BEST) kidney study, analyzing current methods of CRRT for AKI among 54 ICUs in 23 countries, showed that CVVHF was used most commonly (52.8 \%), followed by CVVHDF (34 \%) and CVVHD (13.1\%) [54]. In Japan, approximately $80 \%$ of patients with AKI in the ICU who require CRRT are treated with CHDF [55]. At present, there is insufficient evidence or consensus to recommend the best RRT treatment modality for patients with AKI requiring RRT, although CRRT may be preferable to IRRT in hemodynamically unstable patients with AKI.

\section{Dialysis membranes for RRT in patients with AKI}

Various dialysis membranes have been used for IHD and CRRT in patients with AKI. These membranes have been classified as biocompatible membranes (BCM) and bioincompatible membranes (BICM). BCM are made of synthetic materials including polyacrylonitrile (PAN), polymethylmethacrylate (PMMA), polyamide (PA), and polysulfone (PS).

BICM are made of unsubstituted cellulose (cupurophane). Exposure of blood to the dialysis membranes during RRT activates complement and cytokines, with $\mathrm{BCM}$ being less active than BICM. Several studies have compared the impact of these two membrane types on mortality among patients with AKI. Six RCTs showed no significant differences in mortality or recovery of renal function between BCM and BICM [56-61]. Thus, KDIGO clinical practice guidelines for acute kidney injury have recommended BCM for IHD and CRRT in patients with AKI [20]. Similarly, a systematic review of seven RCTs comparing mortality in patients undergoing RRT with BCM and BICM revealed that the use of unsubstituted cellulose membranes should be avoided in patients with AKI [62]. A recent inclusive meta-analysis by the Cochrane Collaboration, analyzing nine RCTs and quasi-randomized controlled trials in 1062 patients with AKI requiring IHD, failed to show that BCM resulted in lower mortality and higher rates of renal function recovery when compared with BICM [63].

\section{Conclusions}

Despite several advances in the diagnosis and treatment for AKI, this condition remains associated with unacceptably high morbidity and mortality during the past few decades. In particular, when severe enough to need RRT, mortality in critically ill patients with AKI is increasing. Although RRT plays an important role in the treatment of AKI, the timing of initiation and discontinuation of RRT has not been established. In addition, previous studies have failed to show that CRRT is the superior to IRRT in patients with AKI or significant differences between BCM and BCIM. Only in terms of optimal dose of RRT for AKI, two recent RCTs demonstrated that high dose of RRT does not lead to the improvement of survival rate in patients with AKI. Further well-designed RCTs are required to optimize RRT for patients with AKI.

\section{Abbreviations}

AKl: acute kidney injury; ATN: Acute Renal Failure Trial Network

BCM: biocompatible membranes; BEST: Beginning and Ending Supportive Therapy; BICM: bioincompatible membranes; CHD: continuous hemodialysis; CHDF: continuous hemodiafiltration; CHF: continuous hemofiltration; 
Cl: confidence interval; CRRT: continuous renal replacement therapy; CVH: continuous veno-venous hemofiltration; CWHD: continuous venovenous hemodialysis; CWHDF: continuous veno-venous hemodiafiltration; CWHF: continuous veno-venous hemofiltration; ED: extended dialysis; EDD: extended daily dialysis; HD: hemodialysis; HDF: hemodiafiltration; HF: hemofiltration; HVHF: high-volume hemofiltration; ICU: intensive care unit; IHD: intermittent hemodialysis; IRRT: intermittent renal replacement therapy; IVOIRE: high volume in intensive care; KDIGO: Kidney Disease: Improving Global Outcomes; OMAKI: Optional Mode of clearance in critically ill patients with Acute Kidney Injury; OR: odds ratio; PA: polyamide; PAN: polyacrylonitrile; PMMA: polymethylmethacrylate; PS: polysulfone; RCT: randomized controlled trial; RENAL: Randomized Evaluation of Normal versus Augmented Level; RR: relative risk; RRT: renal replacement therapy; SCr: serum creatinine; SLED: sustained low-efficiency dialysis; SOFA: Sequential Organ Failure Assessment; SSCG: Surviving Sepsis Campaign Guidelines; SVHF: standard volume hemofiltration; vs.: versus.

\section{Competing interests}

The authors declare that they have no competing interests.

\section{Authors' contributions}

SN made the substantial contributions to the study conception and design, and acquisition analysis, and interpretation of the data. DK, SK, YI, and TS helped to draft the manuscript. All authors read and approved the final manuscript submitted for publication.

\section{Authors' information}

SN is an associate professor in the Division of Nephrology, Department of Internal Medicine, Wakayama Medical University. SN, DK, SK, YI, and TS are physicians specializing in nephrology, blood purification, and renal replacement therapy in critical care. DK is a section chief in the Division of Blood Purification Medicine, Kinan Hospital. TS is a director and professor in the Division of Nephrology, Department of Internal Medicine, Wakayama Medical University.

\section{Acknowledgements}

None. No funding to declare.

\section{Author details}

'Division of Nephrology, Department of Internal Medicine, Wakayama Medical University, 811-1 Kimiidera, Wakayama-City, Wakayama-Prefecture 641-8509, Japan. 'Division of Blood Purification Medicine, Kinan Hospital, Wakayama, Japan.

Received: 18 February 2016 Accepted: 8 April 2016

Published online: 27 June 2016

\section{References}

1. Uchino S, Kellum JA, Bellomo R, Doig GS, Morimatsu H, Morgera S, et al. Acute renal failure in critically ill patients: a multinational, multicar study. JAMA. 2005;294:813-18.

2. Mehta RL, Pascaul MT, Soroko S, Savage DR, Himmelfarb J, Ikizler TA, et al. Spectrum of acute renal failure in the intensive care unit:the PICARD experience. Kidney Int. 2004;66:1613-21.

3. Tolwani A. Continuous renal-replacement therapy for acute kidney injury. N Engl J Med. 2012;367:2505-14.

4. Bouman CSC, Oudemans-Van Straaten HM, Tijssen JGP, Zandstra DF, Zandstra DF, Kesecioglu J. Effccts of early high-volume continuous venovenous hemofiltration on survival and recovery of renal function in intensive care patients with acute renal failure: a prospective, randomized trial. Crit Care Med. 2002;30:2205-11.

5. Sugahara S, Suzuki H. Early start on continuous hemodialysis therapy improves survival rate in patients with acute renal failure following coronary bypass surgery. Hemodial Int. 2004;8:320-25.

6. Liu KD, Himmelfarb J, Paganini E, Ikizler TA, Soroko SH, Mehta RL, et al. Timing of initiation of dialysis in critically ill patients with acute kidney injury. Clin J Am Soc Nephrol. 2006;1:915-19.

7. Bagshaw SM, Uchino S, Bellomo R, Morimatsu H, Morgera S, Schetz M, et al. Timing of renal replacement therapy and clinical outcomes in critically ill patients with severe acute kidney injury. J Crit Care. 2009;24:129-40.
8. Shum HP, Chan KC, Kwan MC, Yeung AWT, Cheung EWS, Yan WW. Timing for initiation of continuous renal replacement therapy in patients with severe septic shock and acute kidney injury. Ther Apher Dial. 2013;17:305-10.

9. Combes A, Bréchot N, Amour J, Cozic N, Lebreton G, Guidon C, et al. Early high-volume hemofiltration vs. standard care for postcardiac surgery shock (the HEROICS study). Am J Respir Crit Care Med. 2015;192:1179-90.

10. Karvellas CJ, Farhat MR, Sajjad I, Mogensen SS, Leung AA, Wald R, et al. A comparison of early versus late initiation of renal replacement therapy in critically ill patients with acute kidney injury: a systematic review and meta-analysis. Crit Care. 2011;15:R72.

11. Uchino S, Bellomo R, Morimatsu H, Morgera S, Schetz M, Tan I, et al. Discontinuation of continuous renal replacement therapy: a post hoc analysis of a prospective multicenter observational study. Crit Care Med. 2009;37:2576-82.

12. Wu VC, Ko WJ, Chang HW, Chen YW, Lin YF, Shiao CC, et al. Risk factors of early redialysis after weaning from postoperative acute renal replacement therapy. Intensive Care Med. 2008;34:101-8.

13. Kawarazaki H, Uchino S, Tokuhira N, Ohnuma T, Namba Y, Katayama S, et al. Who may not benefit from continuous renal replacement therapy in acute kidney injury. Hemodial Int. 2013;17:624-32.

14. Ronco C, Bellomo R, Homel P, Brendolan A, Dan M, Piccinni P, et al. Effects of different doses in continuous veno-venous haemofiltration on outcomes of acute renal failure: a prospective randomised trial. Lancet. 2000;356:26-30.

15. Saudan P, Niederberger M, De Seigneux S, Romand J, Pugin J, Perneger $T$, et al. Adding a dialysis dose to continuous hemofiltration increases survival in patients with acute renal failure. Kidney Int. 2006;70:1312-7.

16. Tolwani AJ, Campbell RC, Stofan BS, Lai KR, Oster RA, Wille KM. Standard versus high-dose CWHDF for ICU-relate acute renal failure. J Am Soc Nephrol. 2008;19:1233-8.

17. The VA/NIH Acute Renal Failure Trial Network, Palevsky PM, Zhang JH, O'Connor TZ, Chertow GM, Crowley ST, et al. Intensity of renal support in critically ill patients with acute kidney injury. N Engl J Med. 2008;359:7-20.

18. The RENAL Replacement Therapy Study Investigators, Bellomo R, Cass A, Cole L, Finfer S, Gallagher M, et al. Intensity of continuous renal-replacement therapy in critically ill patients. N Engl J Med. 2009;361:1627-38.

19. Prowle JR, Schneider A, Bellomo R. Clinical review: optimal dose of continuous renal replacement therapy in acute kidney injury. Crit Care. 2011;15:207-14.

20. The Kidney Disease: Improving Global Outcomes (KDIGO) Work Group. KDIGO Clinical Practice Guideline for Acute Kidney Injury. Kidney Int Suppl 2012;2:1-138.

21. Fujii T, Namba Y, Fujitani S, Sasaki J, Narihara K, Shibagaki Y, et al. Low-dose continuous renal replacement therapy for acute kidney injury. Int J Artif Organs. 2012;35:525-30.

22. Uchino S, Toki N, Takeda K, Ohnuma T, Namba Y, Katayama S, et al. Validity of low-inensity continuous renal replacement therapy. Crit Care Med. 2013;41:2584-91.

23. Cole L, Bellomo R, Journois D, Davenport P, Baldwin I, Tipping P. High-volume haemofiltration in human septic shock. Intensive Care Med. 2001;27:978-86.

24. Reiter K, D'Intini V, Bordoni V, Baldwin I, Bellomo R, Tetta C, et al. High-volume hemofiltration in sepsis. Nephron. 2002;92:252-58.

25. Joannes-Boyau O, Honoré PM, Perez P, Bagshaw SM, Grand H, Canivet JL, et al. High-volume versus standard-volume haemofiltration for septic shock patients with acute kidney injury (IVOIRE study): a multicentre randomized controlled trial. Intensive Care Med. 2013;39:1535-46.

26. Lehner GF, Wiedermann CJ, Joannidis M. High-volume hemofiltration in critically ill patients: a systematic review and meta-analysis. Menerva Anestesiol. 2014:80:595-609.

27. Clark E, Molnar AO, Joannes-Boyau O, Honoré PM, Sikora L, Bagshaw SM. High-volume hemofiltration for septic acute kidney injury: a systematic review and meta-analysis. Crit Care. 2014;18:R7.

28. Schiffl $H$, Lang SM, Fischer R. Daily hemodialysis and the outcome of acute renal failure. N Engl J Med. 2002;346:305-10.

29. Faulhaber-Walter R, Hafer C, Jahr N, Vablbruch J, Hoy L, Haller H, et al. The Hannover Dialysis Outcome study: comparison of standard versus intensified extended dialysis for treatment of patients with acute kidney injury in the intensive care unit. Nephrol Dial Transplant. 2009;24:2179-86.

30. Claure-Del Granado R, Macedo E, Chertow GM, Soroko S, Himmelfarb J, Ikizler TA, et al. Effluent volume in continuous renal replacement therapy overestimates the delivered dose of dialysis. Clin J Am Soc Nephrol. 2011:6:467-75

31. Vesconi S, Cruz DN, Fumagalli R, Kindgen-Milles D, Monti G, Marinho A, et al. Deliverde dose of renal replacement therapy and mortality in critically ill patients with acute kidney injury. Crit Care. 2009;13:R57. 
32. Misset B, Timsit JF, Chevret S, Renaud B, Tamion F, Carlet J. A randomized cross-over comparison of the hemodynamic response to intermittent hemodialysis and continuous hemofiltration in ICU patients with acute renal failure. Intensive Care Med. 1996;22:742-6.

33. Mehta RL, McDonald B, Gabbai FB, Pahl M, Pascual MT, Farkas A, et al. A randomized clinical trial of continuous versus intermittent dialysis for acute renal failure. Kidney Int. 2001;60:1154-63.

34. John S, Griesbach D, Baumgärtel M, Weihprecht H, Schmieder RE, Geiger $H$. Effects of continuous haemofiltration vs intermittent haemodialysis on systemic haemodynamics and splanchnic regional perfusion in septic shock patients: a prospective, randomized clinical trial. Nephrol Dial Transplant. 2001;16:320-7.

35. Gašparović V, Filipović-Grćić I, Merkler M, Pišl Z. Continuous renal replacement therapy (CRRT) or intermittent hemodialysis (IHD)- what is the procedure of choice in critically ill patients? Ren Fail. 2003;25:855-62.

36. Augustine JJ, Sandy D, Seifert TH, Paganini EP. A randomized controlled trial comparing intermittent with continuous dialysis in patients with ARF. Am J Kidney Dis. 2004;44:1000-7.

37. Kielstein JT, Kretschmer U, Ernst T, Hafer C, Bahr MJ, Haller H, et al. Efficacy and cardiovascular tolerability of extended dialysis in critically ill patients: a randomized controlled study. Am J Kidney Dis. 2004;43:342-9.

38. Kumar VA, Yeun JY, Depner TA, Don BR. Extended daily dialysis vs. continuous hemodialysis for ICU patients with acute renal failure: a two-year single center report. Int J Artif Organs. 2004;27:371-9.

39. Uehlinger DE, Jakob SM, Ferrari $P$, Eichelberger M, Huynh-Do U, Marti HP, et al. Comparison of continuous and intermittent renal replacement therapy for acute renal failure. Nephrol Dial Transplant. 2005;20:1630-7.

40. Vinsonneau C, Camus C, Combes A, de Beauregard MA C, Klouche K, Boulain $T$, et al. Continuous venovenous haemodiafiltration versus intermittent haemodialysis for acute renal failure in patients with multiple-organ dysfunction syndrome: a multicentre randomised trial. Lancet. 2006;368:379-85.

41. Abe M, Okada K, Suzuki M, Nagura C, Ishihara Y, Fujii Y, et al. Comparison of sustained hemodiafiltration with continuous venovenous hemodiafiltration for the treatment of critically ill patients with acute kidney injury. Artif Organs. 2010;34:331-8.

42. Lins RL, Elseviers MM, Van der Niepen P, Hoste E, Malbrain ML, Damas P, et al. Intermittent versus continuous renal replacement therapy for acute kidney injury patients admitted to the intensive care unit: results of a randomized clinical trial. Nephrol Dial Transplant. 2009;24:512-8.

43. Baldwin I, Bellomo R, Naka T, Koch B, Fealy N. A pilot randomized controlled comparison of extended daily dialysis with filtration and continuous veno-venous hemofiltration: fluid removal and hemodynamics. Int J Artif Organs. 2007;30:1083-9.

44. Abe M, Maruyama N, Matsumoto S, Okada K, Fujita T, Matsumoto K, et al. Comparison of sustained hemodiafiltration with acetate-free dialysate and continuous venovenous hemodiafiltration for the treatment of critically ill patients with acute kidney injury. Int J Nephrol. 2011;2011:432094.

45. Schwenger V, Weigand MA, Hoffmann O, Dikow R, Kihm LP, Seckinger J, et al. Sustained low efficiency dialysis using a single-pass batch system in acute kidney injury - a randomized interventional trial: the REnal Replacement Therapy Study in Intensive Care Unit PatiEnts. Crit Care. 2012;16:R 140.

46. Schefold JC, von Haehling S, Pschowski R, Bender T, Berkmann C, Briegel S, et al. The effect of continuous versus intermittent renal replacement therapy on the outcome of critically ill patients with acute renal failure (CONVINT): a prospective randomized controlled trial. Crit Care. 2014;18:R11.

47. Wald R, Friedrich JO, Bagshwaw SM, Burns KE, Garg AX, Hladunewich MA, et al. Optimal mode of clearance in critically ill patients with acute kidney injury (OMAKI)-a pilot randomized controlled trial of hemofiltration versus hemodialysis: a Canadian Critical Trial Group project. Crit Care. 2012;16:R205.

48. Kumar VA, Craig M, Depner TA, Yeun YY. Extended daily dialysis: a new approach to renal replacement for acute renal failure in the intensive care unit. Am J Kidney Dis. 2000;36:294-300.

49. Marshall MR, Golper TA, Shaver MJ, Alam MG, Chatoth DK. Sustained low-efficiency dialysis for critically ill patients requiring renal replacement therapy. Kidney Int. 2001;60:777-85.

50. Rabindranath KS, Adams J, MacLeod AM, Muirhead N. Intermittent versus continuous renal replacement therapy for acute renal failure in adults. Cochrane Database Syst Rev 2007;3:CD003773.

51. Dellinger RP, Levy MM, Rhodes A, Annane D, Gerlach H, Opal SM, et al. Surviving sepsis campaign: international guidelines for management of severe sepsis and septic shock:2012. Crit Care Med. 2013;41:580-637.
52. Schneider AG, Bellomo R, Bagshaw SM, Glassford NJ, Lo S, Jun M, et al. Choice of renal replacement therapy modality and dialysis dependence after acute kidney injury: a systematic review and meta-analysis. Intensive Care Med. 2013;39:987-97.

53. Zhang L, Yang J, Eastwood GM, Zhu G, Tanaka A, Bellomo R. Extended daily dialysis versus continuous renal replacement therapy for acute kidney injury: a meta-analysis. Am J Kidney Dis. 2015;66:322-30.

54. Uchino S, Bellomo R, Morimatsu H, Morgera S, Schetz M, Tan I, et al. Continuous renal replacement therapy: a worldwide practice survey. The Beginning and Ending Supportive Therapy for the Kidney (B.E.S.T. Kidney) Investigators. Intensive Care Med. 2007:33:1563-70.

55. Kaizu K, Inada Y, Kawamura A, Oda S, Hirasawa H. Current status of blood purification in critical care in Japan. Contrib Nephrol. 2010;166:4-10.

56. Schiffl H, Lang SM, König A, Strasser T, Haider MC, Held E. Biocompatible membranes in acute renal failure: prospective case-controlled study. Lancet. 1994;344:570-2.

57. Jones $\mathrm{CH}$, Goutcher E, Newstead CG, Will EJ, Dean SG, Davison AM. Hemodynamics and survival of patients with acute renal failure treated by continuous dialysis with two synthetic membranes. Artif Organs. 1998;22:638-43.

58. Jörres A, Gahl GM, Dobis C, Polenakovic MH, Cakalaroski K, Rutkowski B, et al. Haemodialysis-membrane biocompatibility and mortality of patients with dialysis-dependent acute renal failure: a prospective randomised multicentre trial. Lancet. 1999;354:1337-41.

59. Gastaldello K, Melot C, Kahn RJ, Vanherweghem JL, Vincent JL, Tielemans C. Comparison of cellulose diacetate and polysulfone membranes in the outcome of acute renal failure. A prospective randomized study. Nephrol Dial Transplant. 2000;15:224-30.

60. Albright Jr RC, Smelser JM, McCarthy JT, Homburger HA, Bergstralh EJ, Larson TS. Patient survival and renal recovery in acute renal failure: randomized comparison of cellulose acetate and polysulfone membrane dialyzers. Mayo Clin Proc. 2000;75:1141-7.

61. Ponikvar JB, Rus RR, Kenda RB, Bren AF, Ponikvar RR. Low-flux versus high-flux synthetic dialysis membrane in acute renal failure: prospective randomized study. Artif Organs. 2001;25:946-50.

62. Pannu N, Klarenbach S, Wiebe N, Manns B, Tonelli M. Alberta Kidney Disease Network. Renal replacement therapy in patients with acute renal failure. JAMA. 2008;299:793-805.

63. Alonso A, Lau J, Jaber BL. Biocompatible hemodialysis membranes for acute renal failure. Cochrane Database Syst Rev. 2008;1:CD005283.

\section{Submit your next manuscript to BioMed Central and we will help you at every step:}

- We accept pre-submission inquiries

- Our selector tool helps you to find the most relevant journal

- We provide round the clock customer support

- Convenient online submission

- Thorough peer review

- Inclusion in PubMed and all major indexing services

- Maximum visibility for your research

Submit your manuscript at www.biomedcentral.com/submit
C BioMed Central 